\title{
Understanding Creolization Through Contextualization and Decontextualization Of Objects Found on Reunion Island
}

\author{
Sally Guilloux-Cooke
}

University of Melbourne, University of Reunion Island

\begin{tabular}{|c|c|}
\hline ARTICLE INFO & ABSTRACT \\
\hline $\begin{array}{l}\text { Keywords: } \\
\text { Creolization } \\
\text { Context } \\
\text { Objects } \\
\text { Ethnography } \\
\text { Reunion Island }\end{array}$ & $\begin{array}{l}\text { This ethnographic study is looking at objects to understand the } \\
\text { Creolization process on Reunion Island. Objects evoke memory, } \\
\text { emotion, imagination and validation. On Reunion Island, objects } \\
\text { from the past, such as during the period of slavery and marronage, } \\
\text { have very often disappeared or left little trace of their existence. This } \\
\text { void has sometimes been interpreted as a part of a 'veil of silence' on } \\
\text { the island around this painful part of history. However, there are } \\
\text { some objects, which were intended for use in one context that have } \\
\text { been (and are still being) decontextualized and put to use in totally } \\
\text { new contexts. At the same time, this process of contextualization and } \\
\text { decontextualization can be applied to the creation of a recently } \\
\text { discovered Kingdom of Marons, which existed in the centre of the } \\
\text { island for over } 200 \text { years. Where the original names in old Malgasy, } \\
\text { which many of the slaves spoke, were turned into similar sounding } \\
\text { French words. This decontextualized the meaning and the original } \\
\text { context. We can also apply the same decontextualization process to } \\
\text { objects such as the Alambic, originally used for distilling rum and } \\
\text { later for essential oils. Sabres used as sacred objects in ceremonies } \\
\text { on Reunion Island, began their life as recycled suspension metal from } \\
\text { old trucks used to transport sugar cane. An examination of these } \\
\text { practices and the role contextualization and decontextualization plays } \\
\text { is a means to understand the process of Creolization on Reunion. }\end{array}$ \\
\hline
\end{tabular}

\section{Introduction}

This paper looks at understanding Creolization through objects found on Reunion Island (Reunion). Reunion offers an interesting perspective on Creolization, having no Indigenous culture. The French colonised it in the mid $17^{\text {th }}$ century, after leaving a group of two French men and ten Madagascan slaves. An entire kingdom, only recently discovered through research undertaken between 2013 and 2016, reveals that a political, social and cultural system was developed in the centre of the island by escaped slaves, or marons from this original group. The maron society existed for nearly 200 years from 1663 to the abolition of slavery in 1848 . However, there exists almost no physical objects other than a memory map, which researchers have developed telling the story of this huge piece of history on Reunion. This memory map, which is now the central piece of an exhibition on marronage on Reunion, is one of several key objects that tells us about how Creolization developed on Reunion through transformation, contextualization and decontextualization. I will be drawing on two other objects, the Alambic - a still originally used in distillation of rum on Reunion, which was re-contextualised and used in making essential oils. The other object I will draw on began as a part of old truck suspension metal, transformed into a sabre used in religious ceremonies on Reunion. These objects also help us see the role creativity plays in the constantly moving process of Creolization.

* Corresponding Author E-Mail Address: sally@beinsync.com.au 
Before discussing these objects in relation to Creolization, I will provide a brief description of Reunion Island within the south west Indian Ocean. I will then define the term Creolization, in particular in relation to Reunion Island. I will provide an explanation of the ethnographic approach I am taking as well as an analysis of relevant object theory and the role they play in ethnographic research. I will explore the concepts of context, re-contextualisation and decontextualization as a means to make sense of how objects play an important role in understanding Creolization on Reunion.

\section{Reunion Island}

Reunion Island forms part of the Mascarene Plateau in the south west Indian Ocean, which includes Mauritius and the Seychelles. It is the site of the world's oldest trans-ocean trading route. Originally, Reunion served as a convenient stop-over point for early traders in the region. It was also visited by pirates who would stash their loot, as there were no inhabitants on the island. It was colonised by the French in the mid $17^{\text {th }}$ century and was called Bourbon, after the King. It was re-named Reunion referring to the joining together (Reunion) of the General Assembly of the Marseilles and the Paris National Guard at the time of the march on the Tuilleries Place. The Revolutionaries in so doing, erased the memory of the monarch. Between 1801 and 1810 it was known as Île Bonaparte (after Napoleon Bonaparte). In 1810 it passed under British rule and then four years later, returned to France. Between 1810 and 1848, the island was again called Bourbon. In 1848 it was re-named Reunion Island and became a French department in 1946. (Ghasarian,C. 2009). Within the context of Reunion today, the name signifies more the coming together of four main distinct and diverse cultures; French, African, Indian and Chinese.

The French brought slaves from Madagascar, East Africa and India to the island to work on the coffee plantations and then later sugar when it was found to be a more resilient plant in cyclonic conditions. Approximately six percent of these slaves escaped into the steep, inaccessible areas of the island. (Prosper, E. 2015). They became what is called a maron. The term 'maron' originated from the Spanish American word 'cimarron'. In the $16^{\text {th }}$ century, this meant a domesticated animal that had escaped and taken refuge in a thicket, bush or grove. French settlers in the $16^{\text {th }}$ century, who lived in the West Indies near the Hispanic-American colonies, borrowed the term 'cimarron'. Over time, the word was Creolized into the term Maron, which came to mean a domesticated animal that had fled into the mountains and become wild again. (Pigeon, G. 2017).

After the abolition of slavery in 1848, indentured workers came from French colonies in India in the 1860s. (Mooneegadoo, K. 2018). Chinese, mainly Hak Ka and Cantonese arrived around this time and later as free settlers as well. There were also smaller numbers of indentured workers from other countries such as Malaysia, Indonesia and even some Pacific Islanders. Muslim Indians arrived as free settlers later. During this period, most of the Marons came down from the high areas of the island and mixed with all these groups, making the process of Creolization much more complex.

\section{Defining Creolization}

Creolization is a culturally creative process. It has also been described as a 'slippery concept', which eludes precision in its definition. For example, if we are describing Creolization in the Caribbean, the definition will be different to that of Creolization on Reunion Island. For Sidney Minz, Creolization in the Caribbean is a process of "indigenization" or "localization". (Baron, R. Cara, A. 2011). However, for Francoise Vergès, a native of Reunion island and academic, Creolization is about a 'bricolage'. It draws freely upon what is available, recreating new content and in new forms, a distinct culture" (Vergès, F. 2007). 
This absence of a universally accepted definition has led to two opposing uses of the term - a universalized definition and a culturally specific one. The universal definition sees Creolization as a cultural process, which has the potential to occur anywhere that cultures meet and interact. The culturally specific definition describes the phenomenon of Creolization as restricted to self-ascribed Creole cultures. This view sees the universalizing concept as diminishing the political strength of the term as the word Creole is about identity and cultural self-determination and the process of Creolization (Bogle, D. 2011).

Christine Chivallon sees the value in looking at Creolization from a universal perspective, however she recognizes that this can also be risky in that it could mask the cultural constructions arising from violent matrix such as slavery. (Chivallon, C. 2008). Chivallon also sees the Creolization process as more important than the product or the cultural production.

"Creolization is not a social creation, which is likely to stabilize but is a process of becoming. Creolization is seen as a process of ongoing adaption to the diversity of the world". (Chivallon, C. 2008).

The Creolization process imagines a future where identity is based on relations, rather than on ancestors, blood or even land. I will return to this concept in the discussion of the creation of the memory map. Glissant sees Creolization not as a fusion of diasporas, which he saw as too static, but as a constant making and re-making of Self-Other. He draws on the DeleuzoGuattarian rhizome theory to develop this further in his Poetics of Relation (Glissant,E.1990). A rhizome is an organism of interconnected living fibres that has no central point or origin, form or unity. A rhizome does not start or finish anywhere. Glissant draws on this to explain that Creolization is unpredictable and unstable (Cohen, R. 2015 p6).

Creolization is also a model used in fields such as anthropology and sociology when referring to a mix of cultures and languages in the early colonial world. It acts as a flexible hypothesis to allow researchers to map different modes of contact and migration patterns in culturally and linguistically diverse communities (Shih, S-M. Lionnet,F. 2011 p3).

\section{Mixed method approach - Ethnography and Grounded Theory}

My approach to this study is to combine ethnography with grounded theory. Schwandt (2007) explains that ethnography is the 'process and product of describing and interpreting cultural behavior'. The element distinguishing ethnography from other forms of research that also use fieldwork methods is the production, or construction of text on 'how culture is portrayed' (Schwandt, T.A. 2007. p.96). While many studies use ethnographic methods, not all do ethnography.

Grounded theory was developed in 1960 by Glaser and Strauss as a move away from what they considered to be the established institutional orthodoxy of the time (Bryant, A. \& Charmaz, K. 2007 p43). They encouraged social researchers to conduct fieldwork without a pre-conceived theory or hypothesis. In taking this non-directional approach, my aim is to build trust and engagement in the research so as to avoid imposition on a culture, which has a history of imposition. Combining these two methods allows me to develop collaborative focused data gathering and sound, ethical research practices.

I am using constructivist grounded theory (Charmaz, K. 2007) to develop a representation of the Creole culture on Reunion. This involves an iterative process of fieldwork, analysis, further field work, and final analysis. The constructivist grounded theory approach (Charmaz, K. 2007) involves taking a reflexive stance while comparing and combining data so that both influences from the fieldwork and my own assumption and experience are addressed. Ultimately, this allows the development of theories on the connections between cultural objects and larger social/cultural structures on Reunion. 


\section{The use of objects in ethnography}

In approaching the study of Creolization on Reunion, I wanted to use objects as a part of my ethnographic research. Objects evoke emotion, memory, history and validation. I have taken a non-directional approach to the object choice, leaving that to the participants. Participants learn about the research through word of mouth. I initially used my existing network of people I knew on the island and this then spiraled out into a wider network. The Creole culture of Reunion is still very much oral-based and so word-of-mouth has proven the most effective means to gain access to participants. I wanted to film the interviews, but this proved almost impossible, as even those people I knew were too shy to be filmed. I resorted to just recording audio and taking observational notes. I conduct interviews with the object present, whenever possible, so as to evoke more of a 'thick description' in my notes. Thick description was introduced by Clifford Geertz (1973 p 10) into ethnographic research, which allows for a much more detailed account of the field work and where the researcher makes explicit the patterns of the culture they are studying and puts them into a context.

After six months and conducting around 18 interviews, I was able to begin creating categories, which linked objects together. This is in keeping with the grounded theory approach. Further collapsing of these categories revealed key themes such as Maronage, distillation, transportation and religious practices. Each of the objects I am presenting are linked to one of these themes and reveal differing aspects of the contextualization, re-contextualization and decontextualization which, I argue, are key components of Creolization on Reunion.

\section{The use of objects in understanding Creolization}

Objects or material culture provide a much broader form of social analysis. Object elicitation methods have been incorporated into many anthropological and sociological studies as a path into people's narratives and memories (Hoskin, J. 1998). Work by Ian Woodward (2001) explores how people provide narrative context for objects. This highlights the need to investigate the relationship between what people say and what they do with objects. How people describe objects is a way to create and develop meaningful relationships towards objects as language and how they can 'define' and 'recast' material culture (Shankar,S. 2006).

Objects allow us to consider from each of their different moments of production, exchange, consumption and very often transformation, especially within different social contexts. This perspective provides an understanding of how people and object histories inform each other. One way of understanding this process is through biography. Both people and objects gather time, movement and change. They are constantly transformed, and these transformations of person and object are linked together (Gosden, C. \& Marshall, Y. 1999). As objects move between people, they gather biographies. However, they do not need to be physically modified to acquire new meanings, nor do they have to be exchanged. It is the context that they are placed under that produces the meaning. In some circumstances, such as in colonial settings a sharp break may occur in a biography, which creates a radical resetting of its meaning.

Work by Kopytoff looks at the commodification of objects. He compares the biography of a human slave who moves into the 'commodity stage'. This stage is lost when they are bought, but they remain a potential commodity (Kopytoff, I. 1986). What Kopytoff leaves out in his analysis is the range of contexts that researchers in the field of sociology, anthropology and historians have identified. Objects can be possessions and tools, signify status and change categories. A shift in context can be the result of people's changing relationship with the object over time. There is also the issue of an object that is quite mundane and does not, within a context, contain much value. They usually do not survive in great numbers and the various contexts they were used in may not have been documented (Dannehl, K. 2017). This lack of evidence, or proof can provide challenges but also pose questions as we will see in the study of the Marronage memory map. 


\section{Contextualization, Recontextualization, Decontextualization and Creativity}

The role of context in the creation of meaning is a discussion shared across a range of disciplines. In cultural studies, Len Ang (1996) talks of 'radical contextualism' or "the impossibility of determining any social or textual meaning outside of the complex situation in which it is produced" (p61). In 1923, Bronislaw Malinowski argued for the importance of a context in his essay, "The problem of meaning in primitive languages". He argued that meaning is dependent on the context of the situation, which he termed, "contextual specification of meaning". He also discusses material culture in terms that are often used in discussing language. He used the example of a stick that might be used for digging, punting, walking or fighting. He said that in all these uses the stick is embedded in different cultural contexts. It is given a different cultural value and often a different name in each of the situations (Malinowski, B. 1948).

Archaeologist Ian Hodder, questions the boundaries of object and context. For example, artefacts found in a cemetery, are they part of the body, the grave, a group of graves, or the cemetery. Anthropologist Nicholas Thomas, suggests that objects and contexts not only define each other, they disrupt and change each other (cited in Burke, P. 2002).

Another aspect that needs to be considered when looking at context is how knowledge that was originally local, produced in a specific context, becomes general. This provides space for recontextualisation and decontextualization. Claude Levi-Strauss referred to this as bricolage, a term used to refer to Creolization on Reunion by scholars such as Francoise Verges.

The concepts of recontextualization and decontextualization can be used to define and understand originality, innovation, invention and creativity. Arthur Koestler in his study of the "act of creation" looks at this. He uses the example of the wine-press, observed by Gutenberg, as being "lifted out of its context" used for a new purpose: printing books. Recontextualization is a way to understand creative adaptions. Koestler argues that the perception of a normally hidden similarity can belong in to two associated contexts. He called this explosive association as "bisociation" (Koestler, A.1969). I shall return to this concept when discussing the Alambic, which was originally used in rum distillation and then later for essential oils.

Investigating context provides a rich source to draw an understanding of how people make sense of an environment and how they position themselves within it by creating context. An examination of the Maron's memory map provides an example of this.

\section{The memory map and understanding Creolization on Reunion Island}

In 2013, a pluri-disciplinary team of researchers set about studying the interior of Reunion Island by using an ethno-linguistic analysis of the toponyms and anthroponyms of the area. The team consisted of historians, anthropologists and linguist of the ancient Malagasy language, and a geomatician. The official settlement of the interior of Reunion Island was founded in 1830 in Salazie, one of the three cirques on the island. However, in the $17^{\text {th }}$ century, all three cirques on Reunion were inhabited by Marons. At this time, approximately $80 \%$ of the slaves were from Madagascar. Despite these slaves coming from eighteen different ethnic groups on Madagascar, they were united by a common language, which was mutually understandable. Pigeon (2017) believes this was the key asset that allowed the Marons to organize and become resistant.

The research team drew on slave-hunter detachment reports, which detailed the paths that the Marons took. The slave hunters were actually private military-detachments or para military organisations. The Governor at the time created these military detachments due to the huge amount of military pressure the Marrons put on the colonisers. This tells us how organised the Maron society was. There were a group of young warriors, called 'Tuk' men, which means secret army. There was a king and a queen that ruled the interior of the island, and there were also many captains and lieutenants. It was organised on a military basis. 
"In fact, symbolically what they were saying is we have run away from your plantations, taken our freedom and organised ourselves" (Pigeon, G. 2019).

At the same time the slave-hunters used the knowledge of those captured slaves who became scouts for the hunters to move around the centre. The main thoroughfare into the remote centre of the island was via the ravines. In the $18^{\text {th }}$ century, there existed no maps of the interior. In fact, it was the Marons that discovered this unknown territory, which is like an island within an island due to its inaccessibility. Even today the cirque of Mafate is only accessible by foot or helicopter.

Isolated islets, or small plateaus formed by erosion of the gully slopes became settlement sites for the Marons. They were usually located at more than 1000 meters above sea level and built close to a water source such as a waterfall or spring. The Marons constructed log cabins on these islets and planted crops such as corn, tubers, beans and taro (Pigeon, G. 2017). The Marons moved between these islets to flee the slave hunters. The slave hunter reports state that this network of islets was regularly maintained as part of the Maron's strategy of camouflage and invisibility. The islets were connected by ravines, corridors and hillsides, which was the 'archipelago' (Pigeon, G. 2017) of what became a Kingdom of Marons.

Part of that organisation, to help in moving around the Kingdom more efficiently, was to create names for significant places and people. The names were originally in Malagasy. They were often highly descriptive of the geography, importance of a place and also of significant people. For example, 'Be Maho' is Malagasy for place of many Maho trees. This tree was vital for their survival as it was used for construction, cooking and also the young shoots are edible. There are no less than seven toponyms for 'Maho'. Sometimes the place names describe the geography of a landmark for example the name 'Tay Bit', which means rabbit poo - because the shape of the mountain looks like rabbit poo. The names can also be for significant people such as the Maron chief or captain of the army, Dimiti. The place where he lived is called Le Plateau de Dimiti. These names give a meaning to the isolated interior of the island and provided a context to move around and communicate within the Kingdom. The use of names in this memory map also highlights one of the key concepts of Creolization on Reunion island, that it is based on people and place not land and blood (Glissant, E. 2011). The names are about what existed within the Kingdom, not back to their origins in Madagascar or Africa. This can be compared to the original names of by the early colonisers of Reunion. The names referred back to France such as 'Bourbon' after the king.

"Creolization requires the forgetting of origins, which survive only as reconstructed and transformed" (Verges, F.2007).

Once the decision to stay on the island was made, the need to create something from scratch, as a group began. Historian Loran Hoarau believes this is where the constant negotiation, which is another key element of Creolization on Reunion, began. The negotiation to name a place in a certain way for example. It is this negotiation that he believes creates the balance between the numerous cultures living on the island. He refers to the Creole expression on Reunion, "Avec qui, na pwin batay", which means, "With 'yes' there is no confrontation" to explain this.

"The mutual agreement that you have to lose some parts of your identity to construct a collective identity and it is this very tension and back and forth negotiation that creates the balance in the society" (Hoarau, L. 2019).

When the slave hunters arrived, they needed to understand how to move around, so they took some of the place names and created their own maps. However, what the researchers discovered is that the names were often 'Frenchified', so they lost their original meaning and became decontextualized. For example, a place named 'Be Louve' In Malagasy 'Be' - means many and 'Louve' means an inheritance. Contextually as a place name, this makes no sense. 
However, the word 'Vouve' -which sounds very similar phonetically, is the word for a trap. In old Malagasy, 'Be Vouve' means place of many traps. The slave-hunters reports talk about the fact that the Marons left booby traps in certain places. So, the context for the name was decontextualized.

The memory map, which has now been developed as a physical map by the researchers, is one of the key objects that have provided evidence of the existence of the Marons on Reunion. However, it is one of very few objects from this period, which is a very puzzling considering it lasted for over 200 years. One explanation for the lack of objects, provided by Giles Pignon, is that the slave hunters burnt the villages after they captured the Marons and took away items such as riffles that could be re-used. There is also the geography of the centre of the island subject to cyclones and floods, which could have washed away remains from the Maron villages. Another reason for the absence of objects is provided by Loran Hoarau, who says that many of these objects would have been re-used in different contexts and therefore trace of its original use and existence lost. He uses the example of some blocks of tiles originally used as ballast on the early sailing ships. They were discarded on arrival to Reunion as bags of sugar replaced them as weight. The tiles were later found in a column used on a house. Objects themselves become creolized.

"Everything was consumed and reused and taken out of its original context" (Hoarau, L. 2019).

The lack of physical evidence has proven problematic and led to speculation by some historians such as the late Fidel Suma that there is a "veil of silence" over this period as part of a coverup of this violent past by the French administration (Fuma, S. 2002). It has also led to people saying that the slavery period on Reunion Island was 'soft' as there are none of the physical objects of violence remaining from this time (Pignon, G. 2019).

The role and importance of the physical evidence that objects hold is exemplified by the existence of a 'Salle Temoin", at the Lazarey on Reunion. The Lazarey was a quarantine centre in the mid- $19^{\text {th }}$ century that everyone arriving on Reunion was sent to for medical assessment before being allowed to circulate. The 'Salle Temoin' or 'Witness room' is a room within this centre, which was originally where nurses dispensed the natural plant-based medicines to patients. This room is the only space within the centre that remains untouched since it was built. It is therefore considered a reliable 'witness' to the past.

Another key component of the history of Reunion, beside the period of Marronage, is the story of rum and sugar cane on Reunion. The next object I will discuss is the Alambic or still, which was originally used in the distillation of rum and then as the industry began to decline it was re-contextualized into distilling natural oils.

\section{From Rum to Geranium Oil - the Alambic story}

At the end of the $19^{\text {th }}$ century what had been the economic pillar of Reunion's economy - sugar cane and the distillation of rum, entered a crisis and caused the need for other export products. Perfumed plants such as geranium, originally from South African and ylang-ylang from Madagascar were introduced to the island around the 1870s. So, the Alambic, which had been used for distilling alcohol, was re-contextualized into distilling essential oils destined for perfume, natural medicine and cooking. The rich soil in the cooler mountainous areas on the of the island, particularly in the west coast and in the cirque of Mafate, proved a perfect climate for the development of geraniums. From the beginning of the $20^{\text {th }}$ century, the culture of essential oils underwent a rapid expansion. (Office National des Forests, 2007).

Today the Alambic is still in use, however to a much lesser degree than in the $20^{\text {th }}$ century. From interviews I conducted around this object, it appears to evoke much emotion and attachment particularly to place as well as people. The first interview I did was with two men 
(Mr. A and Mr. B), unknown to each other. They both had a strong association with the Alambic and grew up in the same area on the island. Mr. A's father had worked at a sugar cane distillation plant and had his own Alambic at home. Mr. B is continuing the two-hundred-year old family geranium distillation tradition using the same Alambic. For both these men, the Alambic evoked a flood of childhood memories. Of descending in the early mornings into the ravine to collect water and carry it back in a bucket on their head. Of gathering up the precious geranium stalks. Of pressing the stalks hard into the Alambic, much like pressing grapes in wine making. Of playing around the fire as it heated the water under the Alambic, which would turn to vapor and perform the magic of extracting the precious oil. Of cooking corn and choko - a green vegetable that grows on vines, found in the ravines. The association of place, with the cooler mountainous area of the island was a strong factor in connecting the two men via the Alambic.

For Madame B, a white Creole woman in her mid-80s, the Alambic that sits majestically in her garden, is an object that connects to her late husband. The Alambic was given to her husband as a gift. He did not use it to distill oil, instead he was fascinated by the process and function of it. So, he redesigned the Alambic in miniature versions and sold them to people around the island. When Madame B spoke about the Alambic it was with great emotion and pride, which provided a physical connection to her husband. Again, the concept of people and place within Creolization was evoked through the interviews around this object.

In considering the re-contextualization of the Alambic, from rum to essential oil distillation, I refer back to the work of Arthur Koestler in his study of the "act of creation" and his example of the wine-press lifted from its original context by Guttenberg and used for printing books (Koestler, A.1969). The use of the Alambic from rum to distillation of natural oils, provides a glimpse at the creativity involved in the process of Creolization and the re-contextualization, which is at play. It provides an understanding of the ingenuity in adapting to changing circumstances and finding associations within differing contexts.

I turn now to de-contextualization through looking at the use of a part of a truck suspension, which has been turned into a sabre used in religious practice. This provides another example of how objects can become 'Creolized' and trace of their origin lost.

Truck suspension to sacred Sabre

The Sabre is an important object used to cut the head of goats in traditional ceremonies on Reunion. After months of research, I was finally rewarded within a two-day period of interviewing the two recognized Sabre makers on Reunion. Both interviews came about by word-of mouth. I first interviewed Gerard Allamele who took me to his workshop on the east of the island. He performs a ritual before he begins making his Sabres. He lights camphor wood, which is sacred in Hindu tradition used for statues and medicine. Its smell is almost intoxicating. He then lights incense around an image of the Goddess Kali, in a small shine he has set up in his workshop. He also beats a drum. He then lights the coal, which will be used to melt the precious metal.

The metal used in the making of the Sabres comes from old trucks used in transporting sugar cane to the factory. They are about fifty years old and increasingly rare. Gerard shows me his pile of 'treasure' as he calls it. The suspension metal, which combines the exact subtleness and strength necessary to make a quality sabre, consists of about ten to fourteen layers of metal in decreasing size. Only the first two layers, called the mistress and the sub-mistress are suitable for making the Sabres. The rest of the metal is used to make parts used in a factory. Just like the body of the goat, which will be sacrificed using the Sabre, nothing will go to waste. The metal is heated and pummeled using a hammer. This takes an enormous amount of energy. Harry Abbezzot, the other sabre maker I met, demonstrated this. After only a few moments of bashing the metal, sweat appears and he is physically exhausted. It takes about a week to make 
a Sabre. The beautiful wooden handle of the Sabre, made from local fruit tree wood, is carved like fine furniture.

The Sabres made on Reunion are unique as they have a metal ball added to the top of the blade. This is very different from Indian Sabres. The ball acts as a brake, preventing damage if it hits material such as cement. It also provides balance. These Sabres are big and weigh about 4 kilos. They need to be this big to cut the head of the goats found on Reunion, which are beautiful animals. They are a special breed mixed with goats from Mauritius and India. Combined with the vegetation grown from the rich volcanic soil on the island, which the goats feed on, the goats are much bigger than those found in India. This means the Sabre has to be bigger too.

The religious ceremonies performed on Reunion are also very different from traditional Indian ceremonies. Gerard explains that they have mixed elements from Muslim Indians, Hindu and Tamil traditions in a Creolized version. The goat's head is cut using a Halal tradition and the goat's soul is asked to be accepted by the Gods in the Hindu tradition. This explains why when Reunion descendants of Indian slaves or indentured workers go to India in search of their origins, they find very different traditions. The Sabre, transformed from suspension metal, is used in ceremonies which also have undergone a transformation within the Reunion Island context.

The Sabre is another example of the ingenious creativity, which is involved in the Creolization process where de-contextualization allows for the recreation of a new object, a new context, a new biography.

\section{Conclusion}

Creolization on Reunion is driven by creativity and adaptability, what has been called a 'bricolage' a 'making do' with what is available. We can see this in the Alambic, where a tool for distilling rum was lifted out of one context and placed in another, driven by the need to adapt to a changing circumstance. Again, we can see that in the example of the production of the Sabre from suspension metal to sacred object. Creolization is also driven by the importance and value placed on people and place as we have seen in the creation of a contextualized memory map during the period of marronage on Reunion, where place names of significant geographic, strategic descriptions or people were created. This map shows us the importance of context and how this provides a meaningful way to communicate important information and at the same time to make sense of an environment. It shows us that once you detach yourself from what you have known, your origins, and then what becomes valuable are your relations between people and place.

Creolization is also about the negotiation between all the cultures that have been brought together on Reunion, that is what creates the unique balance between the distinct and diverse cultures and what drives this ongoing process on Reunion. I believe that the little-known island of Reunion offers the world a unique perspective on how diversity can drive creativity and how Creolization provides an opportunity to see the importance and value of relations between people and place within a space.

\section{Acknowledgements}

I would like to thank the research team that created the Marronage Memory Map for their valuable work and contribution to this article: Gilles Pignon, Laurent Hoarau, Sylvain Dumont Ah-Line, Charlotte Rabesahala and Jean-Cyrille Notter.

\section{References}

Ang, I. (1996) Living room wars: rethinking Media Audiences for a Postmodern World. London. Routledge. 
Baron, R. \& Cara, A. (2011) A. Introduction: Creolization as Cultural Creativity. Creolization of Cultural Creativity. University Press of Missisippi pp 1- 13.

Bogle, D. (2011) Creolization as cultural creativity. Caribbean Quarterly. Vol 60 Issue 2, pp $153-155$.

Bryant, A. and Charmaz, K. (2007) Introduction to Grounded Theory Research: Methods and Practices. Sage Handbook of Grounded Theory. Sage Publications.

Burke, P. (2002) Context in Context. Common Knowledge: 8:11. Duke University Press.

Charmaz, K. (2007). Grounded theory. In J.A Smith (Ed) Qualitative Psychology: A practical guide to research methods pp $81-110$. USA: Sage.

Charmaz, K. \& Mitchell, R.G. (2001) "Grounded theory in Ethnography, in Atlinson, P., Coffey, A Delmont, S., Lofland, J and Lofland, L. (Eds). Handbook of Ethnography Sage, London pp $16-176$.

Chivallon, C. (2008). The Notion of Creolization: An Attempt at Theoretical clarification. Diaspora. 17:1pp $18-41$.

Clinanoo (2012). Les mille et un sabres de Gerard Allamele-Ranganayaguy. By Cynthia Tevane, 26 July 2012.

Cohen, R. (2015). Seeds, roots, rhizomes and epiphytes: botany and diaspora. Diasporas Reimagined Spaces, Practices and Belongings. Sigona et al. Oxford Diasporas Program. Oxford Department of International Development pp 2-8.

Dannehl, K. (2017) From production to consumption. In - History and Material Culture: a student's guide to approaching alternative sources. Karen Harvey \{ed\}. 2nd Edition Imprint Routledge. London. pp171-186.

Dilley.RM. (1999) The problem of context. Perspectives from Social Anthropology and Elsewhere. New York: Berghahn Books, pp1-46.

Fuma,S. (2002) L'esclavage et le marronage a la Reunion. Futura-sciences.com www.futurasciences.com/magazines/sciences/infos/dossiers/d/ethnologie-esclavagemarronnagereunion-158/ viewed 24 April 2019.

Geertz, C. (1973) Interpretations of Culture. Basic Books, USA. P 10.

Ghasarian, C. (2009) Power and Beliefs on Reunion Island. Indian Ocean Studies: Cultural, Social and Political Perspectives. Edited by Moorthy, S \& Jamal, A. Taylor and Francis.

Glisssant, Édouard (2011). "Creolisation and the Americas.” Caribbean Quarterly, vol. 57, no. 1. pp. 11-20.

Gosden, C. and Marshall, Y. (1999). The cultural biography of objects. World Archaeology. Vol 31 [2] pp 169-178.

Hoarau, L. (2019) Objects and Creolization on Reunion Island. Interviewed by Sally GuillouxCooke. Saint Denis. 7 May 2019.

Hoskins, J. (1998) Biographical Objects: How Things Tell the Stories of People's Lives. London: Routledge.

Koestler, A. (1969). The Act of Creation. Rev. Ed. London: Hutchinson. p123

Kopytoff, I. (1986) The Cultural Biography of things: Commodification as a process. In Appadurai $\{$ ed $\}$ The social life of things. Cambridge [Cambridgeshire]; New York: Cambridge University Press, c1986. pp 64-5. 
Malinowski, B.(1948) "Culture" in Encyclopedia of Social Sciences. Ed. Edwin. R. A. Selignam \{1930:2 ${ }^{\text {nd }}$ edition, New York: Macmillan, pp 621-645.

Malinowski, B.(1923) The Problem in Meaning in Primitive Languages. In The Meaning of Meaning. Ed. Charles K Ogden and I.A. Richard \{London: Routledge and Kegan Paul. pp 451-510.

Miles, M.B \& Huberman, A.M. (1994) Qualitative data analysis: An expanded sourcebook USA: Sage.

Mooneegadoo,K.(2018) Maintenance of Ancestral Patterns of Belief and Behaviour in Mauritius and Reunion - A comparative Diasporic Outlook. Language in India. Vol 18:10 pp 333-340

Mr. A and Mr. B (2019). Interview on the Alambic. Petit France. La Reunion. 26 April 2019.

Office National des Forests (2007) Le Geranium Rosat, Senteur des Haut (http://www.onf.fr)

Pigeon, G. (2017) Marooning: to refuse slavery on the isle of Bourbon in the $18^{\text {th }}$ century. Our Ocean Guide. Lightbox Publishing. Venice, Italy. pp 251 - 265.

Pigeon, G. (2019) The Maron Memory Map. Interviewed by Sally Guilloux-Cooke. Saint Denis Reunion Island 15 July 2019.

Prosper, E. (2015) La societe, bourbannaise, p15 in CRESOL - Centre de researches sur la societies de l'ocean Indien. Website:www.cresol.fr/De-Bourbon-a-la-Reunion- 1-historie.

Shankar, S. (2006) Metaconsumptive practices and the circulation of objectifications. Journal of Material Culture 11(3): pp 293-317.

Shieh, S-M \& Lionnet, F (2011) Creolization of Theory. Duke University Press pp 3 -35.

Schwandt, T.A (2007) The Sage dictionary of qualitative inquiry, $3^{\text {rd }}$ ed. USA Sage.

Trueba, H. \{1981-2\}. The meaning and use of context in Ethnographic Research: Implications for Validity. NABE Journal. Vol V1, Nos 2 and 3.

Vergès, F. (2007) Indian-Oceanic Creolizations: Processes and Practices of Creolization on Réunion Island Stewart, C (ed.) 2007, Creolization: History, Ethnography, Theory. Taylor \& Francis Walnut Creek. pp $135-160$.

Woodward, I. (2001) Domestic objects and the taste epiphany: a resource for consumption methodology. Journal of Material Culture 6(2): pp 115-136. 